\title{
Mastoid surgery: a high-risk aerosol generating surgical procedure in COVID-19 pandemic
}

\author{
Santosh Kumar Swain*, Rohit Agrawala
}

\begin{abstract}
Department of Otorhinolaryngology, IMS and SUM hospital, Siksha “O” Anusandhan University, K8, Kalinga Nagar, Bhubaneswar, Odisha, India.
\end{abstract}

Received: 05 August 2020

Accepted: 14 September 2020

\section{*Correspondence:}

Dr. Santosh Kumar Swain,

E-mail:santoshvoltaire@yahoo.co.in

Copyright: (c) the author(s), publisher and licensee Medip Academy. This is an open-access article distributed under the terms of the Creative Commons Attribution Non-Commercial License, which permits unrestricted non-commercial use, distribution, and reproduction in any medium, provided the original work is properly cited.

\begin{abstract}
Corona virus disease 2019 (COVID-19) is highly contagious disease occurred by the severe acute respiratory syndrome corona virus 2 (SARS-CoV-2) which spreads human to human through respiratory secretions. It was declared as public health emergency all over the world. There is lack of data in relation to the otologic or mastoid surgery during COVID19 pandemic. Aerosolization of the novel corona virus SARS-CoV-2 is associated with middle ear and mastoid surgery. So, the safety precautions are important parts in this present pandemic time for preventing transmission of the infections to the surgeon and team members of the surgery. Preoperative screening for COVID-19 is must for safety of the surgeon and team members. The mastoid surgery on the positive, suspected or unknown status for COVID-19 patients need protection with adequate Personal protection equipment (PPE) such as disposable cap, N95 respirator and sealed eye protection or Powered air-purifying respirator (PAPR), disposable gown and gloves. In the mastoid surgery, there is scarcity of the medical literature related to the transmission of the novel corona virus SARS-CoV-2and its prevention during present COVID-19 pandemic. So, the aim of this review article is to increase awareness among the otolaryngologists for preventing the viral exposure during the mastoid surgery.
\end{abstract}

Keywords: COVID-19, Mastoid surgery, Otologic surgery, Safety precautions

\section{INTRODUCTION}

Otolaryngologists play an indispensable role in coronavirus disease 2019 (COVID-19) pandemic because they often deal with ear, nose, oral cavity and throat. Ear, nose and throat are part of the upper airway which produce aerosols and cause transmission of the infections to the health care workers at the outpatient clinic and Operation room (OR). Mastoidectomy is a very old surgical procedure done by otolaryngologists for treatment of the chronic otitis media, cochlear implant and acute otitis media with mastoiditis. ${ }^{1}$ Otolaryngologists are often vulnerable to COVID-19 infection because of the surgical procedures in the mastoid and middle ear which are contiguous with the upper respiratory tract. $^{2}$ The exponential transmission of the COVID-19 without proper medications and vaccine are making a great challenge for all the health care professionals. The experiences of COVID-19 pandemic at China, Italy, Iran, United States of America and India show that otolaryngologists are amongst the highest risk medical professionals for receiving the contaminations of this virus during the routine procedures. ${ }^{1}$ There is concern of viral transmission during the otological procedures such as mastoid surgery by high speed drill which thought to be an aerosol generating surgery. There is potential risk for transmission of the virus to the surgeon and the team members in the $\mathrm{OR}$ and need a higher level of personal protections. There are different techniques can be used such as barrier drapes and wearing adequate PPE can significantly reduce the dispersion of the aerosols producing during mastoidectomy. Appropriate precautions with use of PPE, face shield, gloves and N95 masks can prevent SARSCoV-2 infection among the otolaryngologists and assisting 
health care staffs. This review article will enhance the awareness among the health care workers specifically otolaryngologists and the OR personnel for preventing transmission during mastoid surgery.

\section{Methods for literature search}

Research articles regarding mastoidectomy in COVID-19 were searched through a multiple approach. First, we conducted an online search of the PubMed, Scopus, Google Scholar and Medline database with the word mastoid surgery or mastoidectomy during COVID-19 pandemic, preventive measures of the surgeon during mastoidectomy, viral transmission, otologic surgery during COVID-19 pandemic and precautions. The abstracts of the published article were identified by this search method and other articles were identified manually from the citations. This review article reviews the COVID19 virus, history, epidemiology, otologic surgery, mastoidectomy, viral transmission, techniques to avoid viral transmission during mastoidectomy. This review article presents a baseline from where further prospective trials can be designed and help as a spur for further research in this clinical entity where not many studies are done. The objective of this review article is to provide a precise and brief knowledge regarding the prevention of the COVID-19 transmission during the mastoid surgery. This article is specially focused for preventing the viral transmission during surgery of the mastoid bone by high speed drill.

\section{DISCUSSION}

\section{COVID-19 virus}

The etiologic agent for this COVID-19 was identified as a novel corona virus which was initially called as acute respiratory syndrome corona virus 2 (SARS-CoV-2) and this disease is called COVID-19 by World Health Organization (WHO). WHO later on named this pathogenic virus as 2019-nCoV. This virus belongs to a group of the highly diverse viruses known as corona viruses, which is an enveloped virus, possessing a single stranded ribonucleic acid (RNA) as its genetic substance. ${ }^{4}$ So far, 2019-nCoV is the 7th member of the corona virus family which can infect human being. The incubation period of Covid-19 ranges from 1 to 14 days with a median of 5-6 days. Although recent study document that the incubation period may extend to 24 days. ${ }^{5}$ A longer incubation has implication in quarantine policies and prevention of the spread of the disease. This virus primarily transmitted via respiratory droplets but also it is found in blood and stool, so raising question regarding mode of transmission. ${ }^{6}$

\section{History}

The initial patient of the pneumonia due to novel corona virus SARS-CoV-2 manifesting COVID-19 was found in Wuhan, Hubei Province, China in December 2019. ${ }^{7}$ Then the infections transmitted from human to human and lead to pandemic with disastrous manifestations all over the world. The aerosol transmission of the virus was observed during the corona virus disease (COVID-19) crisis, specifically after doing endoscopic hypophysectomy at the Wuhan, China which infected the novel corona virus to 14 staffs of the surgical team. ${ }^{8}$ In that surgery, the drilling system was used for hypophysectomy which created profuse aerosols during the surgery followed by inhalation to the upper airway of the surgical team. The corona viruses were detected in middle ear infection already way back in $1998 .{ }^{9}$ However, very little knowledge known to medical professionals about the behavior of the new SARS-CoV-2 in the middle ear.

\section{Epidemiology}

WHO has declared COVID-19 as pandemic disease on March 11, 2020 and COVID-19 spread to around 199 countries by March 26, 2020 with more than 462680 positive cases and approximately 20834 deaths. ${ }^{10}$ The epidemic of the COVID-19 showing a grim and tragic situation worldwide in present days. It is affecting on the global economy along with daily clinical practice of a clinician. It is also seriously affecting routine Otorhinolaryngology practice and specifically surgical intervention of the routing and emergency diseases impacting person's quality of the life. Over a week, the COVID - 19 spread to Asian countries, to Europe and then America and finally all over the world with a rapid doubling time (6.4 days). ${ }^{11}$ It was declared as a public health emergency by WHO on 20th January 220. Majority $(81 \%)$ of the patients is asymptomatic or present only mild symptoms whereas approximately $15 \%$ show severe forms those need hospitalization. ${ }^{12}$ Approximately 3 to $4 \%$ of the cases require respiratory support in an Intensive care unit (ICU). The mortality or death rate is around 0.39 to $4 \%$ but it depends on the age of the patients and it is more in elderly patients older than 70 years. ${ }^{12}$ The transmission of this virus mainly occur by symptomatic patients, however it has been also documented in asymptomatic persons and those are in incubation period which can last more than 14 days. ${ }^{12}$ These asymptomatic individuals are source of occult transmission.

\section{Viral transmission in otologic surgery}

The SARS-CoV-2 is very infectious virus. The novel corona virus SARS-CoV-2 transmission usually occur by droplets from the mucus or aerosolized particles during the clinical examination or performing surgery in the areas of the infected or contaminated mucosa or epithelium. Middle ear cleft mucosa including the mucosa lining the mastoid air cells lining are considered as part of the upper respiratory airway in terms of the lining epithelium. ${ }^{13}$ The middle ear cleft consisting of the eustachian tube, middle ear, aditus and mastoid antrum with air cells. This middle ear cleft connecting the nasopharynx by eustachian tube to the mastoid air cells and antrum by aditus. ${ }^{14}$ So, the viral transmission from the nasopharynx is easily transmitted to 
the middle ear and mastoid antrum. Drilling of the mastoid can cause clouding of the irrigation and bone dusts which can easily come in contact with facial skin and also inhaled by the surgeon and assisting staff. The COVID-19 infection process is divided into three stage such as stage I: asymptomatic patient with or without detectable virus; stage II: mild symptomatic patient with presence of the virus; stage III: severe respiratory symptoms along with high viral loads. ${ }^{15}$ In COVID-19, the viral transmission usually occurs through respiratory system, there is also evidence for blood borne transmission. ${ }^{16}$ The otological procedure ranges from routine or elective to certain emergency procedures. The tympanoplasty, ossiculoplasty, stapedotomy, cortical mastoidectomy and modified radical mastoidectomy are considered as elective surgery whereas chronic otitis media with impeding intracranial complications, vertigo or sudden facial paralysis are thought as procedure which requires interventions on the urgent basis (table 1$).{ }^{17}$ However, the concern is risk of the viral transmission in the present COVID-19 pandemic. It is now a big challenge for surgeon to decide for performing the otologic or mastoid surgery. Dry cough and fever are important clinical manifestations of the COVID-19 patients. So, these clinical presentations should be searched from the patients of the otologic disease consulting for mastoid surgery. Otolaryngologists may encounter nasal congestions, rhinorrhea, sore throat, cough, hyposmia, dysgeusia, dyspnea, edematous tonsils, enlarged neck nodes or dizziness among the patients with COVID-19.

\section{Otologic diseases}

There are numerous otological diseases for which patient consult the otolaryngologists or otologists. The diseases vary from simple middle ear infections to atticoantral diseases with life threatening complications. The otological diseases are often detected earlier and usually before landing into life threatening complications. However, sudden life-threatening complications of the ear disease occur rarely. Certain acute life-threatening diseases of the ear need urgent mastoid exploration. In case of the mastoiditis with sub-periosteal abscess, surgery can be performed within 48 to 72 hours. ${ }^{17}$ If there are symptomatology for sepsis, the surgery can be done faster, especially sepsis make the surgery as emergency one. Certain otologic disorders can be deferred on the basis of the clinical manifestation of the patients but in few cases, it depends on the comfort area of the responsible otologists. However, in COVID-19 pandemic, dealing with such otologic disease may land in transmission of the COVID-19 infections to the health care workers. Mastoid exploration often required with use of a high-speed drill for managing the complicated otological diseases. When there is no time for doing COVID-19 screening test, the patient should be considered as potentially COVID-19 positive and so the necessary and the best protective measures should be used by the surgeon as per guidelines.

\section{COVID-19 screening test before mastoid surgery}

Real time polymerase chain reaction (RT-PCR) is a definitive test for detecting viral nucleic acid of COVID19 and acts as standard investigation for screening of this disease despite its false negative rate. Performing mastoid surgery in COVID-19 require preoperatively a thorough screening of the patients in terms of the diagnostic screening and eligibility screening of the patient. Even the COVID-19 test is negative it might still be relevant for taking precautions as it is associated with high false negative rate. The surgery is to be planned if the benefits of the surgical interventions outweigh the risk of the infections to the OR personnel. The operating time is in $\mathrm{OR}$ and exposure of the surgical procedure to $\mathrm{OR}$ personnel should be minimized as much as possible. In case of mastoid surgery, imaging of the temporal bone can be done. When CT scan of the temporal bone is done, a limited dose screening of thorax can be done simultaneously. Pulmonary COVID-19 lesions are easily detected by the CT scan of the thorax even in the asymptomatic patients and it is consider as more sensitive test than RT-PCR for screening purpose. ${ }^{18} \mathrm{CT}$ thorax plays an important role for early diagnosis of COVID-19 and provides decision towards performing the surgery at earliest. However, the surgeon any how will adopt COVID-19 precautions, so the CT scan of the thorax will provide added value for anesthesiologist towards ventilation of the patient during the surgery period. When there is less or no time for waiting of COVID-19 screening report, the patient should be considered as potentially COVID-19 positive and surgery done with best protective precautions as per hospital guidelines. Even the COVID19 report is negative; it might still be necessity to take precautions because of high chance of false negative rate. Rapid COVID-19 screening is an ideal method for diminishing the risk of transmission of the infections to the OR staffs. The risk of infection transmission should be assessed as per risk stratification protocols. Proper use of N95 masks and PPE should be used whenever required.

\section{Anesthesia prospective}

The major challenge for anesthesiologists is to deal with patients of suspected or a confirmed case of COVID-19. A dedicated OR is required for COVID-19 positive cases. The OR should be maintained with negative pressure. There should be systematic check list and appropriated areas for donning and doffing. Adequate hypotensive anesthesia is helpful to reduce bleeding at the time of the mastoid surgery and minimize the related aerosolization of the blood and other mastoid fluids. The anesthetists and the team should wear N95 mask, caps, face shield, protective goggles, disposable gowns and gloves during intubation and extubation. ${ }^{19}$ Patient with pneumonia can be deferred for the mastoid surgery. In case of patient with false negative COVID-19 underwent surgery under general anesthesia, the mechanical ventilation can worsen the status of the COVID-19 in the patient or may cause more severe. 


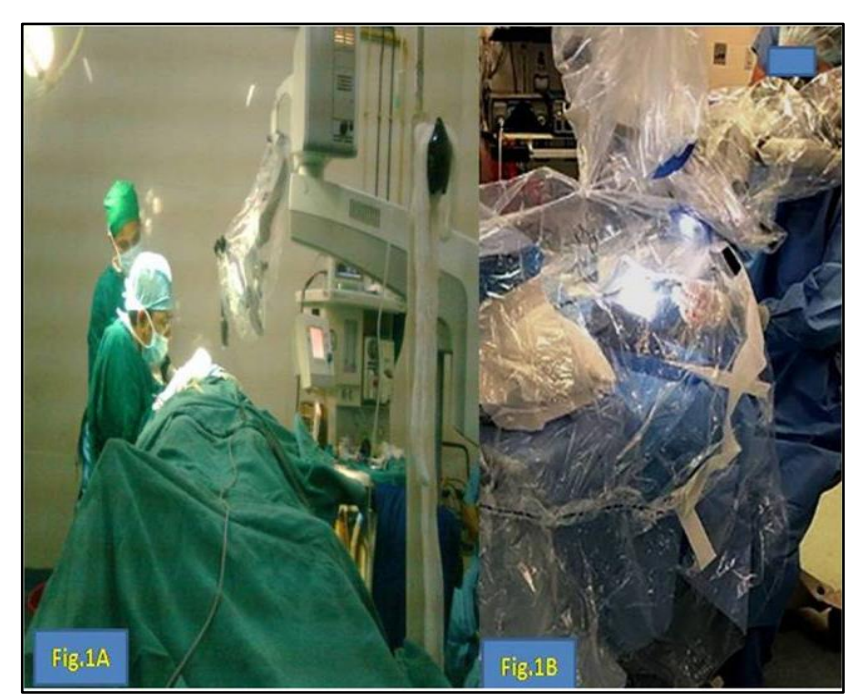

Figure 1: (A) Performing cortical mastoidectomy without under microscope (before COVID-19 pandemic); (B) Performing mastoidectomy under microscope with steri-drape of the microscope (during COVID-19 pandemic).

\section{Mastoidectomy}

During mastoid surgery, spreads of aerosols are more which potentially transmit the virus. The exact definition of the aerosol is considered as an elusive in the literature which represents ranges of the particle sizes less than five micron in diameter which remain in the air for prolonged period causing air borne spread of the virus. ${ }^{20}$ Cortical mastoidectomy is usually done in case of complications with acute otitis media and chronic otitis media. A classic mastoid surgery or mastoidectomy needs a high-speed drill for accessing to the mastoid. The surgeon should analyze why to use a high-speed drill as use of it inevitably associated with significant aerosolization of the bone dusts and other tissue during the drilling. ${ }^{21}$ Although the viral particles are transmitted by respiratory system, there is still some evidence for blood-borne transmission. ${ }^{22}$ So minimal blood loss during surgery also help to reduce transmission of the infections. Piezoelectric drill can be an alternative with minimal aerosolization although not quantified. ${ }^{23}$ If possible, chisel and hammer can be used for drainage of the mastoid empyema or acute mastoiditis instead of the drill for lowering the aerosolization of the bone dusts. The infections of the mastoid usually weaken the bony cortex, so can be easily managed by curettes. The bony microspicules which are generated from the mastoid bone during drilling may penetrate the cornea in animal study and acts as vector for the transmission of the virus. ${ }^{24}$

\section{Manpower in operation room}

Skilled and experienced surgeon should try to perform the mastoid surgery in the absence of residents or interns for decreasing the surgical time and to avoid risk of contaminations to the observers or assisting residents. No student observers are allowed in the theater. The other team members are also best reduced to experienced staffs in terms of scrub nurse, circulating nurse, anesthetists and surgeon. All should work under strict COVID-19 precautions as per guideline issued from the hospital or guidelines by WHO. There should be special attention for doing strictly reduced number of door movements and entry of unnecessary personnel/visitor to the OR. Writing such as "COVID-19 contaminated" should be pasted in the OT door to warn personnel. Filtering facepiece (FFP3) masks with protective goggles or face shield or FFP2 in case of limited resource can be used by the surgical team during the mastoid surgery. The surgeon should wear face shield as eye protection is not sufficient for preventing ophthalmic transmission during the mastoid surgery without under microscope. Although transmission of the viral particle of COVID-19 from the tears are unlike but there are reports for transmission of the corona virus from tears via spectacle. ${ }^{25}$ During micro-ear or mastoid surgery, surgeon often use operating microscope. The use of the face shield may be difficult during seeing through the microscope. So, touching the eye lids to the eye piece of the microscope can transmit the infections. So customized self-made protection shields may be used on the outer surface of the sterile microscope cover at the eye piece/lens. Use of the exoscope can be used if available. Otoendoscope is also a good option in present situation for visualizing the middle ear, sinus tympani, mastoid cavity and other inaccessible area of the middle ear cleft.

\section{Techniques to avoid transmission of the viral particles}

Use of the powered drills generates profuse aerosols and small bony particles with high chance of transmission of the infection. ${ }^{26}$ Performing mastoidectomy without under microscope disperse the bony particles or droplets to the surrounding by 360 degrees and highest dispersion to the surgeon and close surgical sites. However, performing mastoidectomy with use of the microscope and irrigation of the saline to the burr in varying direction may reduce the dispersions of the particles or percent of the surface area with droplets. Use of the barrier drape example: Oto Tent (commercially available barrier drape) significantly reduce the dispersion of the particle density and percent surface area in comparison to the mastoidectomy without or with microscope. ${ }^{27}$ The microscope is usually covered with microscope drape whereas in another technique, there are two different transparent drapes which are attached to the lens cap apparatus such as steri-drape and another one is $\mathrm{C}$-armor (Figure 1). The steri-drape is attached to the microscope by adhesive along the split and then zipped to itself and the surgeon put the arms under the drape. The Carmor is attached by creating 4 to $5 \mathrm{~cm}$ incision on the drape and then stretching tightly around the microscope lens cap cover apparatus of the microscope drape. ${ }^{28}$ As the larger size drape, both forearms are inserted via two small cuts in the drapes for keeping a tight fit. Both the drapes are then stretched over the Mayo stand at the head of the patient. The clear drapes are attached to the surgical drape over the chest of the patient which limits the spread of the aerosols towards anesthetists. Mastoid surgery can be done 
as usual under the both drapes along with added methylene blue after the chosen drape.

\section{Precautions}

Mastoidectomy is often an elective surgery and can be deferred till control of the severe infections in this pandemic. Rapid COVID-19 screening is helpful to diminish the chance of infections to the surgical staff however the false negative, especially with asymptomatic carrier can transmits the virus to the surgeons and staffs. ${ }^{29}$ The risk of the viral transmissions will be minimized by use of the proper N95 mask and PPE. Use of the face shield is difficult during performing mastoidectomy under microscope. Extra precautions are required during ear surgery for preventing the transmission of the virus, specifically at the time of the high-speed drills during mastoidectomy. High speed drills have a great chance for aerosolization particles in the operating room. So, the health care professionals in the operating room have high risk of the virus transmission. Mastoid surgery or mastoidectomy is a high-risk aerosol producing surgical procedure. It has significant potential for exposing to the surgeon and staffs of the operating room. The strategies for preventing the transmission of the virus include adequate PPE use with head, face and neck covering of the drapes which limits the spread of the infection particles generated by the high-speed drilling.

\section{CONCLUSION}

Performing mastoid surgery is a challenge for surgeon in COVID-19 pandemic as it produces profuse aerosols. The aerosols can transmit the viral particles to the surgeon and other team members. Majority of the otologic procedures are considered as elective and can be delayed during this pandemic period. But in certain situations, patients need urgent surgical procedure. No urgent otologic or mastoid surgery should be postponed. The life threatening otologic disease may need urgent mastoid exploration or even performed within 24 hours of the onset of the symptoms. The surgeon should wear N95/FFP3 mask, face shield, disposable and fluid resistant gloves and proper gown/PPE while performing the mastoid surgery.

Funding: No funding sources

Conflict of interest: None declared

Ethical approval: Not required

\section{REFERENCES}

1. Givi B, Schiff BA, Chinn SB, Clayburgh D, Iyer NG, Jalisi $\mathrm{S}$ et al. Safety recommendations for evaluation and surgery of the head and neck during the COVID19 pandemic. JAMA Otolaryngology- Head \& Neck Surgery. 2020;146(6):579-84.

2. Swain SK, Nahak B, Mohanty JN. Pediatric tympanoplasty: Our experiences in a tertiary care teaching hospital of Eastern India Medical Journal of Dr. DY Patil Vidyapeeth. 2020;13(3):229.
3. Zhu N, Zhang D, Wang W, Li X, Yang B, Song J. A novel coronavirus from patients with pneumonia in China, 2019. New England Journal of Medicine. 2020;382(8):727-33.

4. He F, Deng Y, Li W. Coronavirus disease 2019: What we know? Journal of medical virology. 2020;92(7):719-25.

5. Bai Y, Yao L, Wei T, Tian F, Jin DY, Chen L et al. Presumed asymptomatic carrier transmission of COVID-19. Jama. 2020;323(14):1406-7.

6. Zhang W, Du RH, Li B, Zheng XS, Yang XL, Hu B et al. Molecular and serological investigation of 2019-nCoV infected patients: implication of multiple shedding routes. Emerging microbes \& infections. 2020;9(1):386-9.

7. Li Q, Guan X, Wu P, Wang X, Zhou L, Tong Y et al. Early transmission dynamics in Wuhan, China, of Novel Coronavirus-infected pneumonia. N Engl J Med. 2020;382:1199-20.

8. China News Weekly. Restore the infection path of "Super Communicator" Wuhan Doctor: the epidemic just started. Article in Chinese (simplified). 2020. Last accessed on April 2020

9. Pitkäranta A, Jero J, Arruda E, Virolainen A, Hayden FG. Polymerase chain reaction-based detection of rhinovirus, respiratory syncytial virus, and coronavirus in otitis media with effusion. J Pediatr. 1998;133:390-4.

10. World Health Organization. Coronavirus Disease 2019 (COVID-19): situation report e 66. https://www.who.int/emergencies/diseases/novelcoronavirus- 2019/situation-reports. Last accessed on

11. Chan KW, Wong VT, Tang SC. COVID-19: An update on the epidemiological, clinical, preventive and therapeutic evidence and guidelines of integrative Chinese-Western medicine for the management of 2019 novel coronavirus disease. The American journal of Chinese medicine. 2020;48(03):737-62.

12. Wu Z, McGoogan JM. Characteristics of and important lessons from the coronavirus disease 2019 (COVID-19) outbreak in China: summary of a report of 72314 cases from the Chinese Center for Disease Control and Prevention. Jama. 2020;323(13):123942.

13. Swain SK, Samal R, Pani SK. Effect of smoking on outcome of tympanoplasty.Indian Journal of Otology. 2011;17(3):120.

14. Swain SK, Pradhan C, Mohanty S, Sahu MC. Comparative study between selective nerve blocks and the intravenous opioids in mastoid surgery. Egyptian Journal of Ear, Nose, Throat and Allied Sciences. 2017;18(2):121-5.

15. Shi Y, Wang Y, Shao C, Huang J, Gan J, Huang X et al. COVID-19 infection: the perspectives on immune responses. Shi Cell Death Differ. 2020;27:1451-54.

16. Wu JT, Leung K, Bushman M, Kishore N, Niehus R, de Salazar PM et al. Estimating clinical severity of COVID-19 from the transmission dynamics in Wuhan, China. Nature Medicine. 2020;26(4):506-10. 
17. Topsakal V, Van Rompaey V, Kuhweide R, Garin P, Barbara M, Li Y et al. Prioritizing otological surgery during the COVID-19 Pandemic. B-ENT. 2020;16:55-8.

18. Hu Z, Song C, Xu C, Jin G, Chen Y, Xu X et al. Clinical characteristics of 24 asymptomatic infections with COVID-19 screened among close contacts in Nanjing, China. Science China Life Sciences. 2020;63(5):706-11.

19. Wong J, Goh QY, Tan Z, Lie SA, Tay YC, Ng SY et al. Preparing for a COVID-19 pandemic: a review of operating room outbreak response measures in a large tertiary hospital in Singapore. Canadian Journal of Anesthesia/Journal canadien d'anesthésie. 2020;11:1-4.

20. Jones R, Brosseau L. Aerosol Transmission of Infectious Disease. Journal of Occupational and Environmental Medicine. 2015;57(5):501-8.

21. Jewett DL, Heinsohn P, Bennett C, Rosen A, Neuilly C. Blood-containing aerosols generated by surgical technique: a possible infectious hazard. Am Ind Hyg Assoc J. 1992;53:228-31.

22. Zhang W, Du RH, Li B, Zheng XS, Yang XL, Hu B et al. Molecular and serological investigation of 2019-nCov infected patients. Emerg Microbes Infect. 2020;9:386-89.

23. Ito $\mathrm{T}$, Mochizuki $\mathrm{H}$, Watanabe $\mathrm{T}$, Kubota $\mathrm{T}$, Furukawa T, AKoike T et al. Safety of ultrasonic bone curette in ear surgery by measuring skull bone vibrations. Otol Neurotol. 2014;35:135-9.
24. Hilal A, Walshe P, Gendy S, Knoles S, Burns H. Mastoidectomy and trans-corneal viral transmission. Laryngoscope. 2005;115(10I):1873-76.

25. Xia J, Tong J, Liu M, Shen Y, Guo D. Evaluation of coronavirus in tears and conjunctival secretions of patients with SARS-CoV-2 infection. Journal of medical virology. 2020;92(6):589-94.

26. Hilal A, Walshe P, Gendy S, Knowles S, Burns H. Mastoidectomy and Trans-Corneal Viral Transmission. The Laryngoscope. 2005;115(10):1873-1876.

27. Chen JX, Workman AD, Chari DA, Jung DH, Kozin E, Lee DJ et al. Demonstration and mitigation of aerosol and particle dispersion during mastoidectomy relevant to the COVID-19 era. Otology \& Neurotology. 2020;41(9):1230-39.

28. Carron JD, Buck LS, Harbarger CF, Eby TL. A simple technique for droplet control during mastoid surgery. JAMA Otolaryngology-Head \& Neck Surgery. 2020;146(7):671-72.

29. Swain SK, Das S, Padhy RN. Performing tracheostomy in intensive care unit-A challenge during COVID-19 pandemic. Siriraj Medical Journal. 2020;5:72.

Cite this article as: Swain SK, Agrawala R. Mastoid surgery: a high-risk aerosol generating surgical procedure in COVID-19 pandemic. Int $\mathbf{J}$ Otorhinolaryngol Head Neck Surg 2020;6:1941-6. 